\title{
Out Of The Box And Into The Field - Interdisciplinary Undergraduate Science Education On A Georgia Barrier Island
}

- Robert K. Vance (Georgia Southern University)

- Jaynie L. Gaskin (Georgia Dept. of Natural Resources)

- 2021 Southeastern Section

- Geological Society of America

- Acknowledgements:

St. Catherines Island Foundation, GA DNR Sea Turtle Cooperative, Georgia Southern University, M. K. Pentecost Ecology Fund 


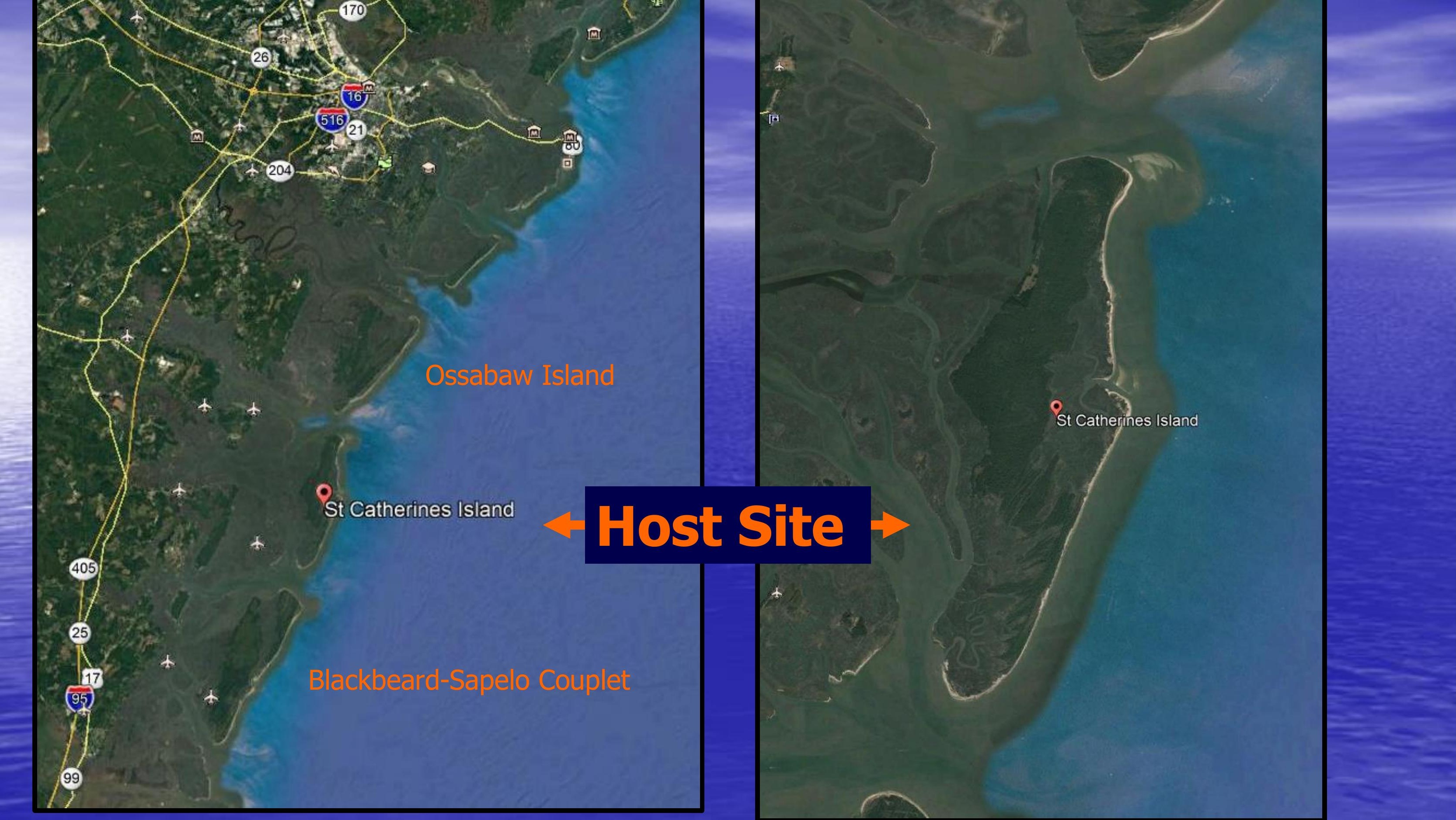




\section{Program Outline}

- July B-Term Course package

- 15 to 18 undergrads enrolled

- Concurrent GEOL 5740 and GEOL 5340 (Sea Turtle Natural History \& Barrier Island Environmental Geology)

- 2-3 days prep lectures at GSU

- 10 days in residence on St. Catherines Island 


\section{GEOL 5740 Sea Turtle Natural History}

- Daily beach monitoring in teams

- Documentation of all sea turtle activity in field journal

- Screen and mark verified nests

- Relocate nest if site is not survivable

- Collect one egg shell for mDNA marking program

- Share team data at debriefing $\rightarrow$ seaturtle.org upload

- Write a paper on loggerhead life cycle and nesting behavior illustrated with images obtained during course 
SLO 1. Apply fundamental geological principles to interpret sea turtle crawlways and nests.

SLO 2. Determine the quality and stability of sea turtle nesting habitat based on recognition of erosional and accretionary geological features on beaches.

SLO 3. Document and describe sea turtle nesting behavior from traces.

$\rightarrow$ SLO 4. Demonstrate improved field methods skills through daily journals and reporting.

$\rightarrow$ SLO 5. Recognize the integration of multiple science disciplines and sub-disciplines in efforts to understand the natural world.

SLO 6. Improve technical writing skills through completion of a paper illustrated with images collected during their work.

SLO 7.Contribute to the conservation of a threatened species through 10 days of beach monitoring. 


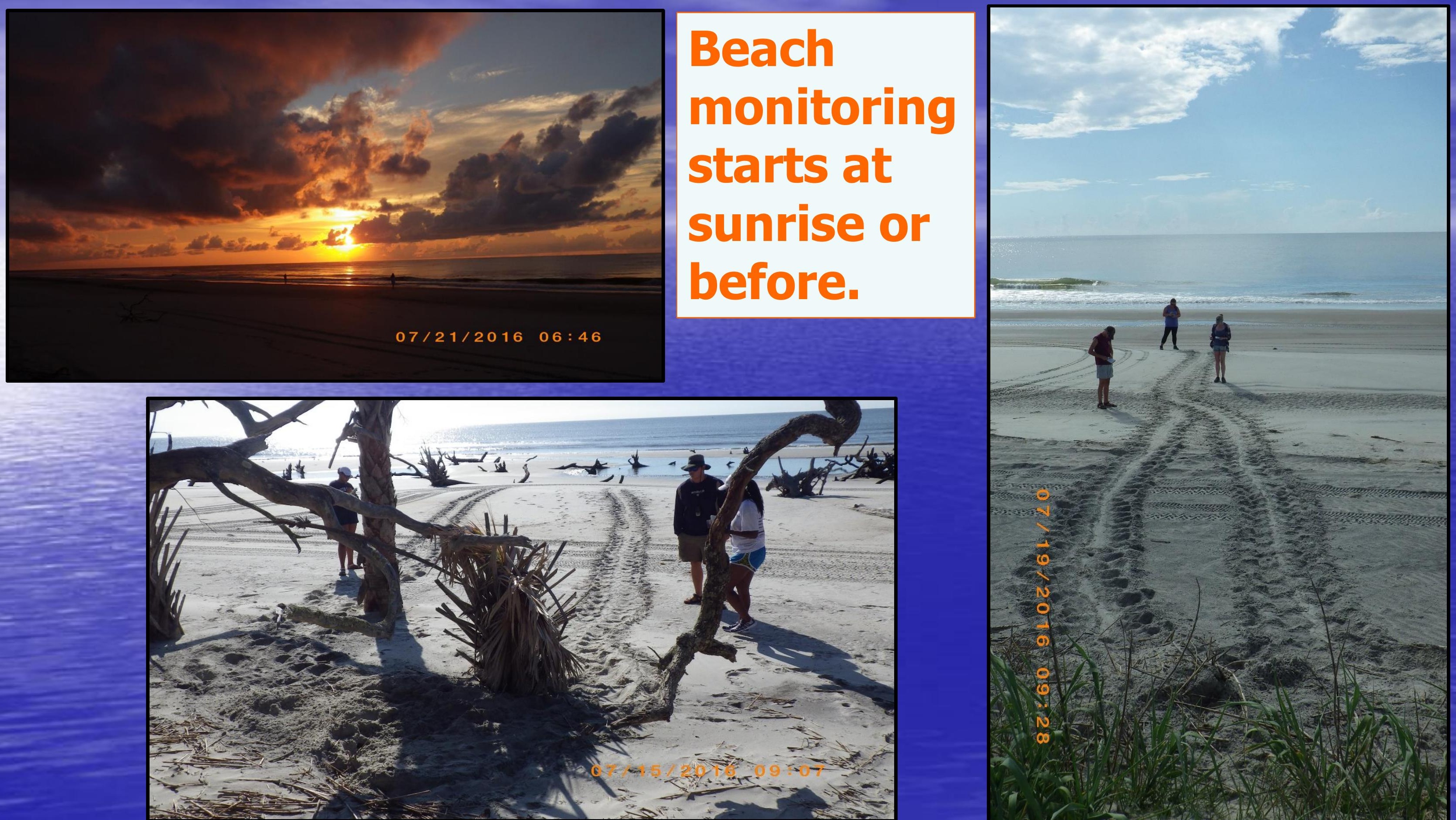


Application of Fundamental Geologic Principles for Conservation Bjology Work

- Cross-cutting Relationships - useful for interpreting biogenic structures as well as discordant geologic structures (faults, dikes, disconformities...)

- Superposicjion - for interpreting animal activity sequences and age of sedimentary deposits 


\section{Application of Fundamental Geologic Principles to Crawlway and Nest Interpretation}

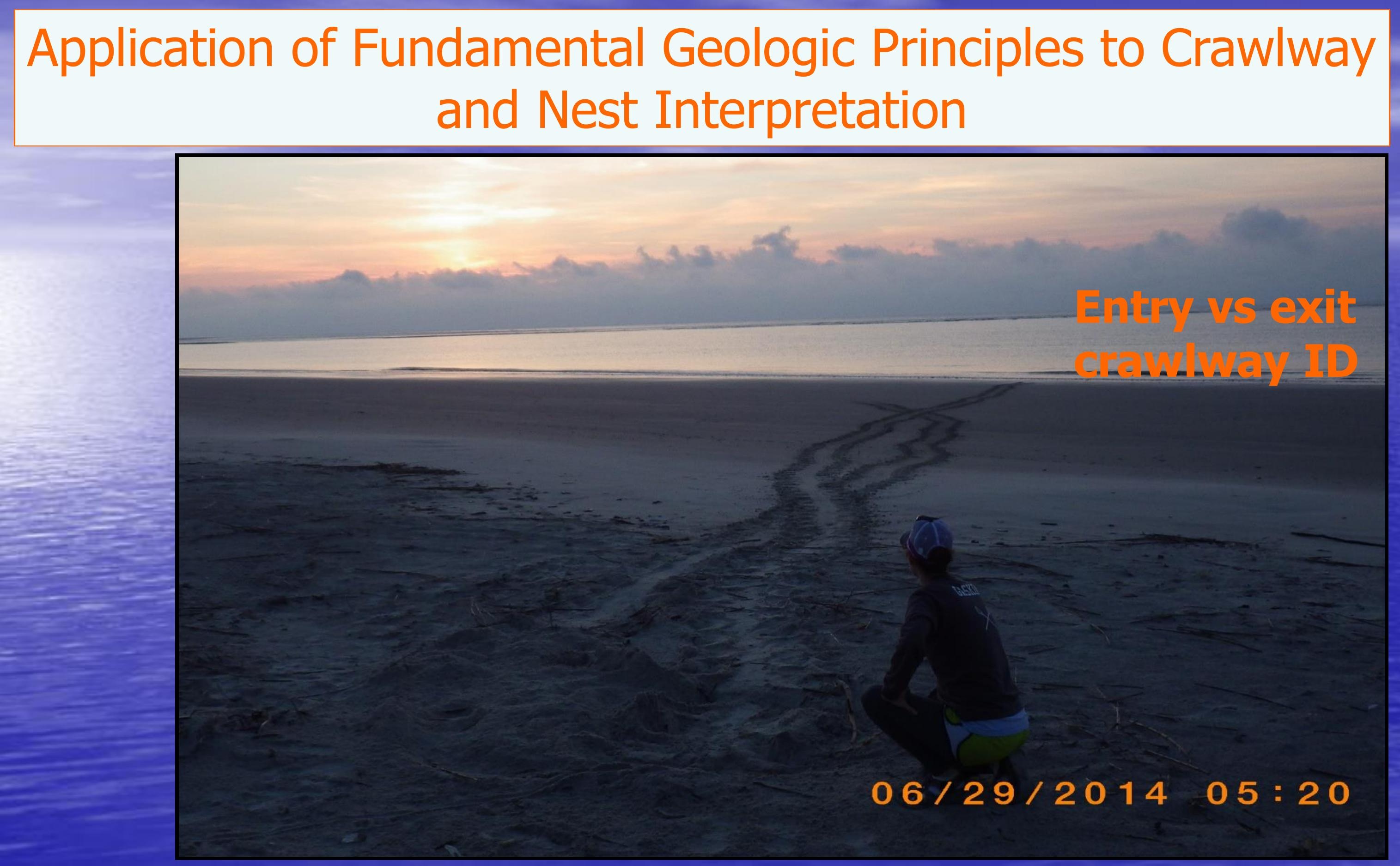

$$
06 / 29 / 201405: 20
$$




\section{Interpretation of Loggerhead sea turtle nests}

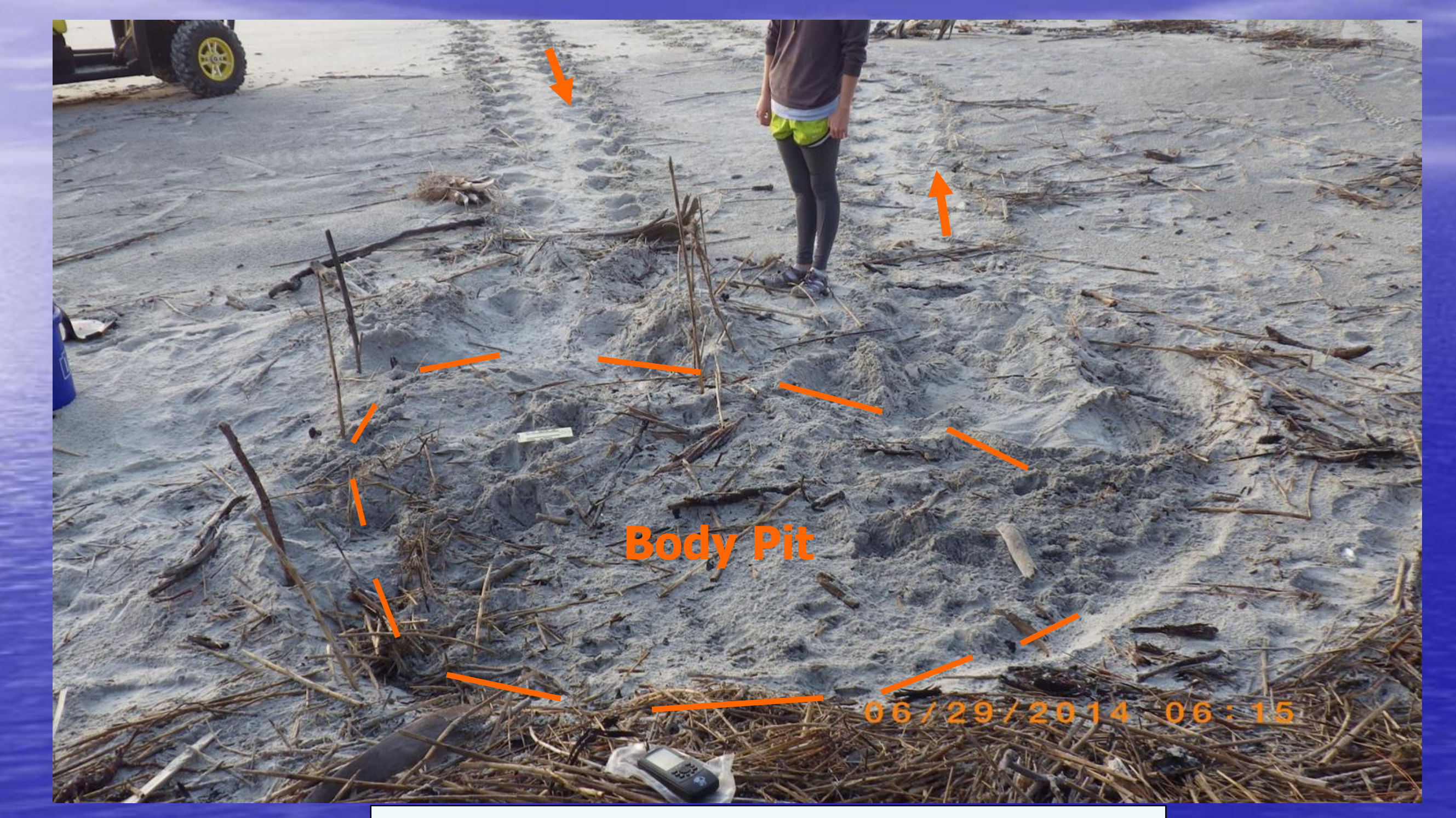

Where is the $\sim 20 \mathrm{~cm}$ diameter egg chamber

within the $\sim 2 \mathrm{~m} \times 1.5 \mathrm{~m}$ body pit??? 


\section{Nest Covering Activity: X-Cutting Relations and Superposition}

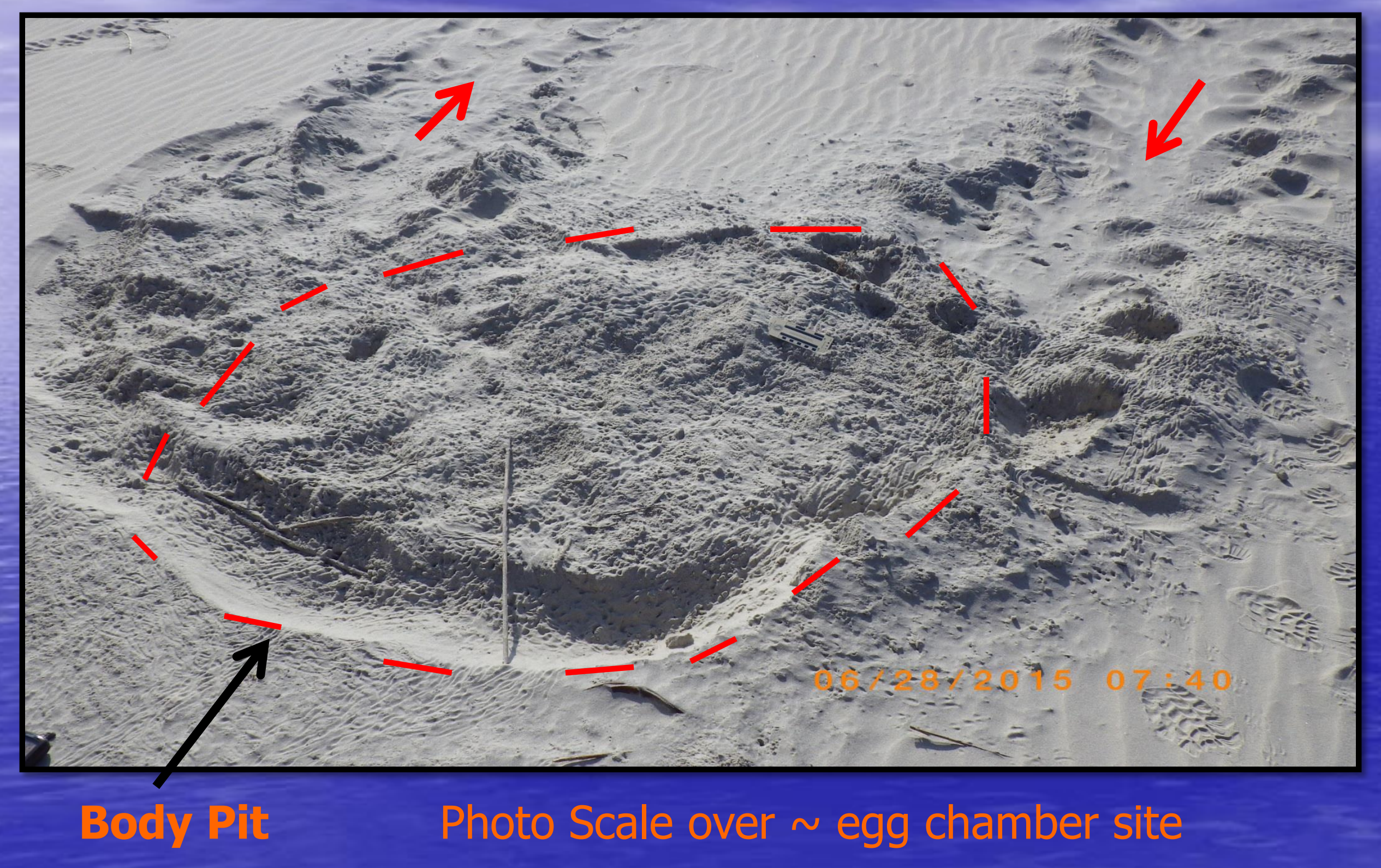




\section{Fundamental}

Geologic

\section{Principles:} Principle of $\mathrm{X}$ Cutting Relationships

Locating the egg chamber within the body pit.

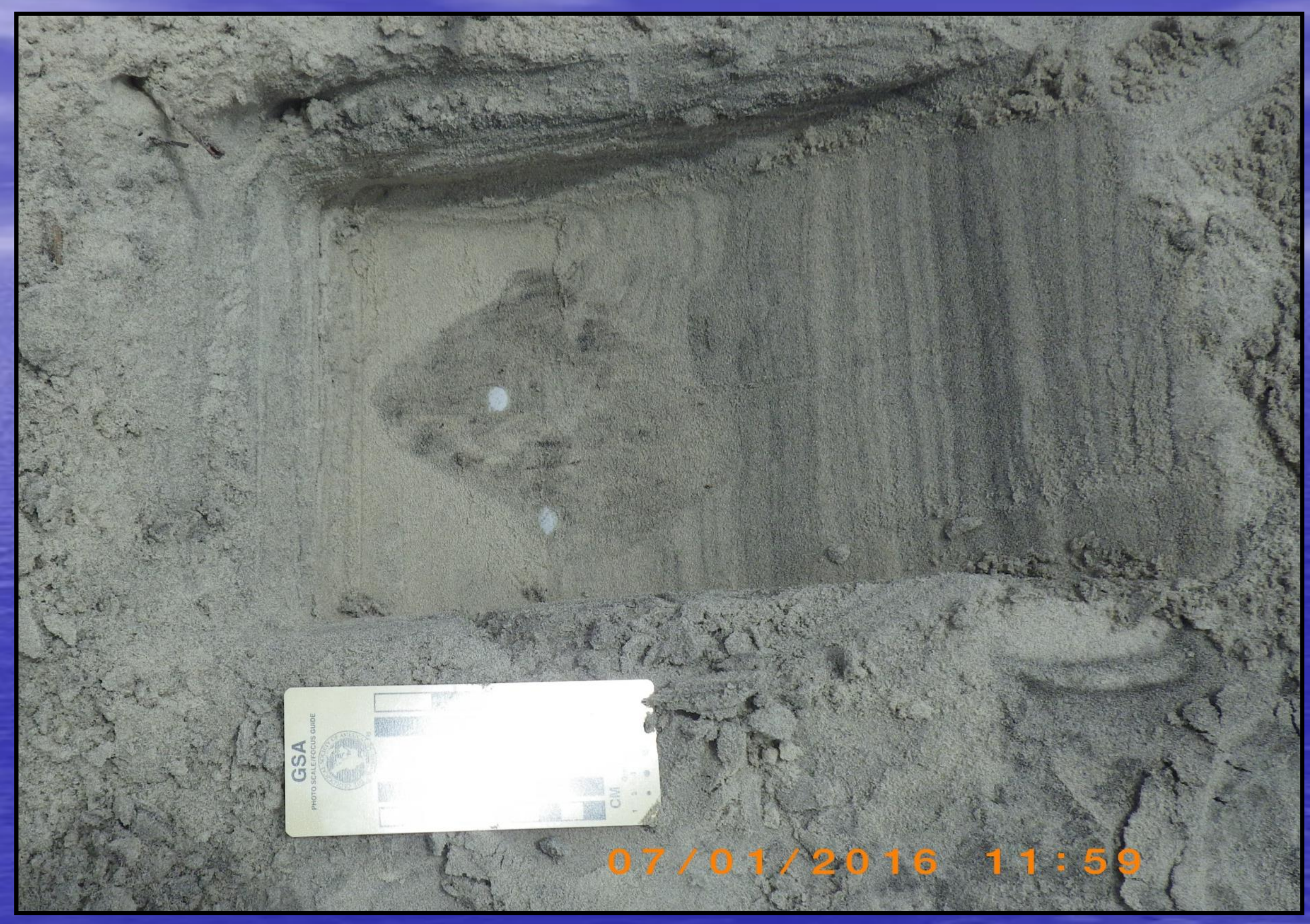


Crossing disciplines: the beach as critical nesting habitat and the forces of coastal geology shaping the beach

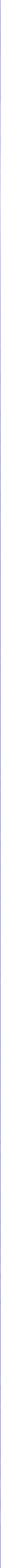




\section{Field Course Flexibility - Teaching Moments}

Necropsy of loggerhead sea turtle by Mark Dodd: anatomy, health assessment, diet, cause of mortality, adaptation to marine environment...

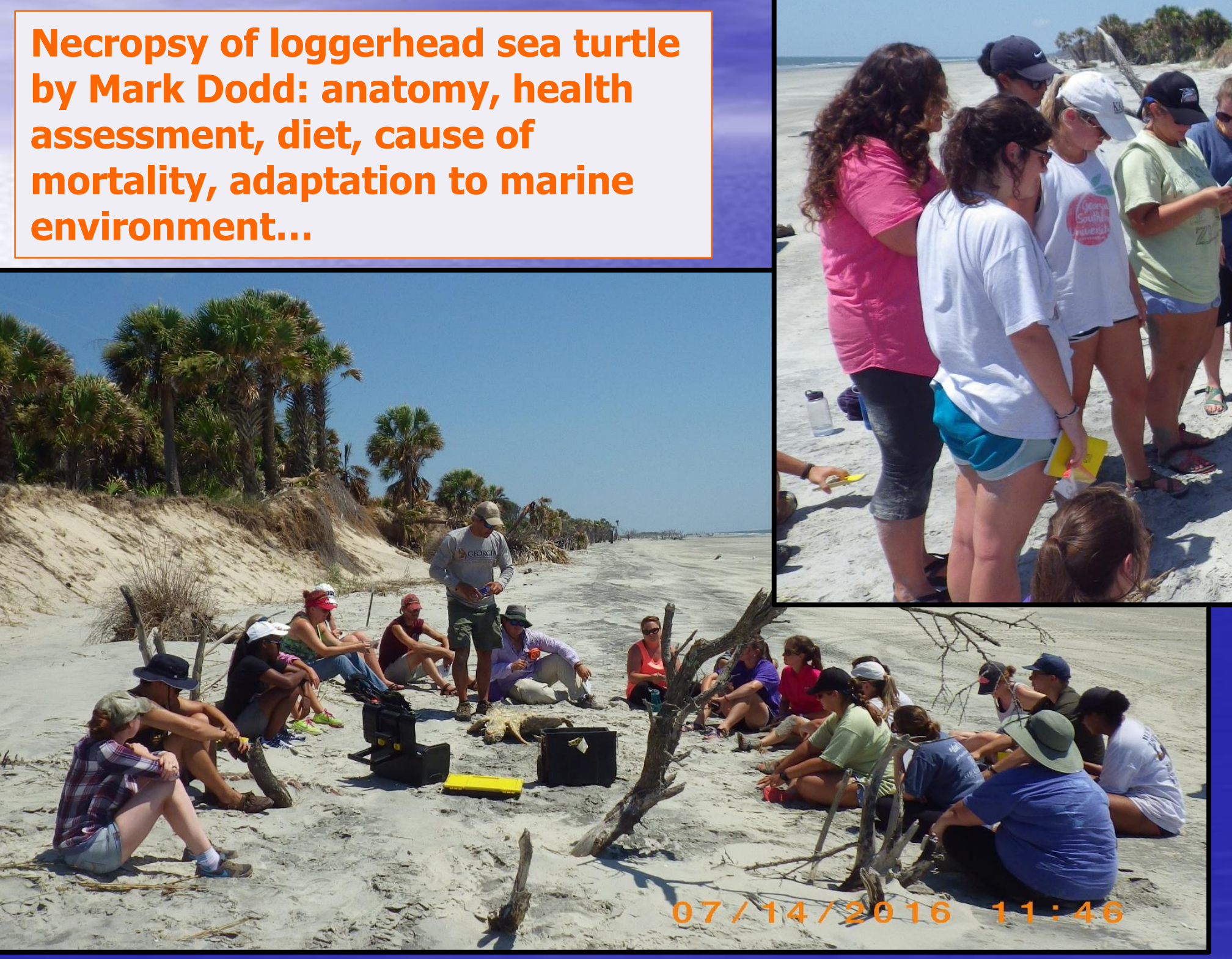




\section{GEOL 5340 Barrier Island Environmental Geology}

o Field Based Research Project - afternoon/evening

- Two person teams

- Oral project presentation during last two nights

- Short research report

- Environmental - geomorphological image collection, site coordinates, map

o Field notes

- Field trips and supplemental lectures.

- Post-course content exam (for both courses) 
SLO 1. Identify the essential geologic and ecologic components of St. Catherines Island and describe the key geologic processes that drive barrier island evolution.

SLO 2. Apply fundamental geologic principles to the interpretation of both geologic and biogenic features.

SLO 3. Observe and document the natural environments and environmental diversity of St. Catherines Island.

SLO 4. Recognize anthropogenic impacts on barrier island environments, hydrology, and natural resources.

SLO 5. Document and describe the effects of sea level rise and shoreline erosion on a barrier island.

SLO 6. Demonstrate field methods skills and critical thinking ability while developing experience in scientific documentation. 


\section{Field Trips and Guest Lectures}

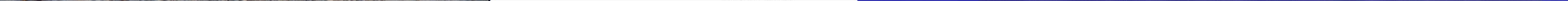




\section{Project Examples}

- Nesting habitat - dune thermal \& moisture measurements

- Water table - ridge and swale environment, depth \& salinity

- Wetlands - salinity and vegetation type

- Tidal flat - faunal survey (species and density)

- Tidal flat - primary sedimentary structure documentation

- Boneyard tidal pools - faunal survey

- Gopher tortoise burrows - heading, length, depth, GPR application

- Beach trash survey - types, amount, projected "life span"

- Dune faunal survey - by tracks and trails

- Beach - thermal and density profiles across tide line 


\section{Examples of student projects...}
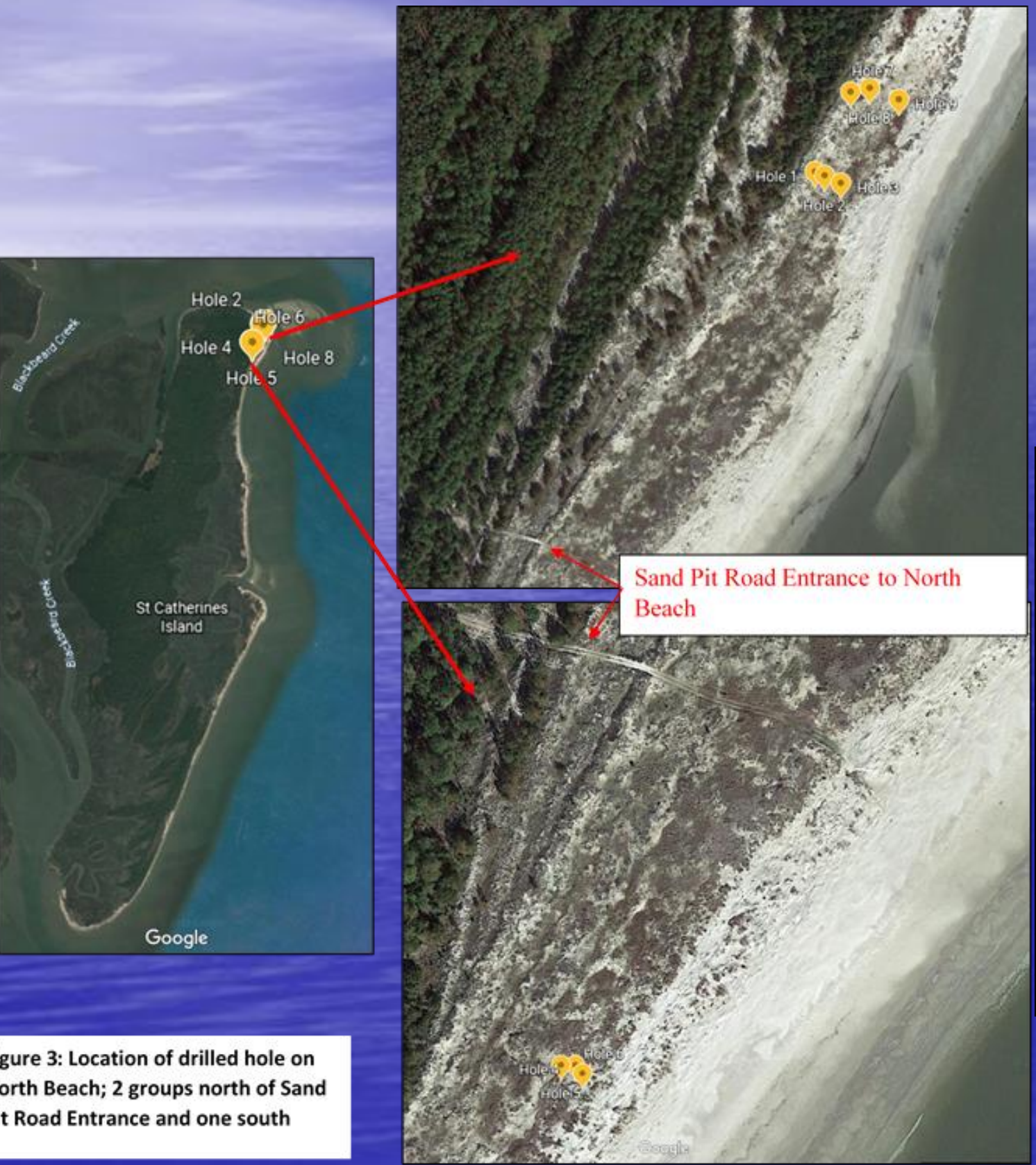

Water Table depth and salinity project by William Laaker and Toby Johnson

\begin{tabular}{|c|c|c|c|c|c|}
\hline Hole \# & Salinity \% & Water Table Depth & Date & Time Taken & Closest Peak Tide (H/L) \\
\hline 1 & $2 \%$ & 3' $1 \frac{1}{4} "$ & $7 / 15 / 2019$ & 7:37 AM & $H-7: 48$ AM \\
\hline 1 & dry & dry & $7 / 15 / 2019$ & 8:14 PM & $\mathrm{H}-8: 26 \mathrm{PM}$ \\
\hline 2 & $1 \%$ & 3' $2 \frac{1}{4} "$ & $7 / 15 / 2019$ & 8:26 PM & $\mathrm{H}-8: 26 \mathrm{PM}$ \\
\hline 3 & $1 \%$ & 3' 1" & $7 / 15 / 2019$ & 9:15 PM & $H-8: 26$ PM \\
\hline 3 & $1 \%$ & $3^{1} 1 / 2 "$ & $7 / 16 / 2019$ & $8: 28 \mathrm{AM}$ & $\mathrm{H}-8: 35 \mathrm{AM}$ \\
\hline 4 & $0 \%$ & $2^{\prime} 7 "$ & $7 / 16 / 2019$ & 8:48 AM & $\mathrm{H}-8: 35 \mathrm{AM}$ \\
\hline 4 & $2 \%$ & 2' $71 \frac{112 "}{}$ & $7 / 16 / 2019$ & 4:27 PM & $L-3: 00 P M$ \\
\hline 5 & $3 \%$ & $2^{\prime} 6 "$ & $7 / 16 / 2019$ & 4:40 PM & $L-3: 00 P M$ \\
\hline 6 & $4 \%$ & 3' 2" & $7 / 16 / 2019$ & 4:50 PM & $L-3: 00 P M$ \\
\hline 7 & $4 \%$ & 3' 3" & $7 / 17 / 2019$ & 10:56 AM & H - 9:19 AM \\
\hline 8 & $3 \%$ & 3' 9" & $7 / 17 / 2019$ & 11:09 AM & $H-9: 19$ AM \\
\hline 9 & $3 \%$ & $3^{\prime} 21 \frac{1}{2 \prime \prime}$ & $7 / 17 / 2019$ & $11: 16$ AM & H - 9:19 AM \\
\hline
\end{tabular}


Technology Application Demonstration - Ground Penetrating Radar (Tracing a Gopher Tortoise Burrow)

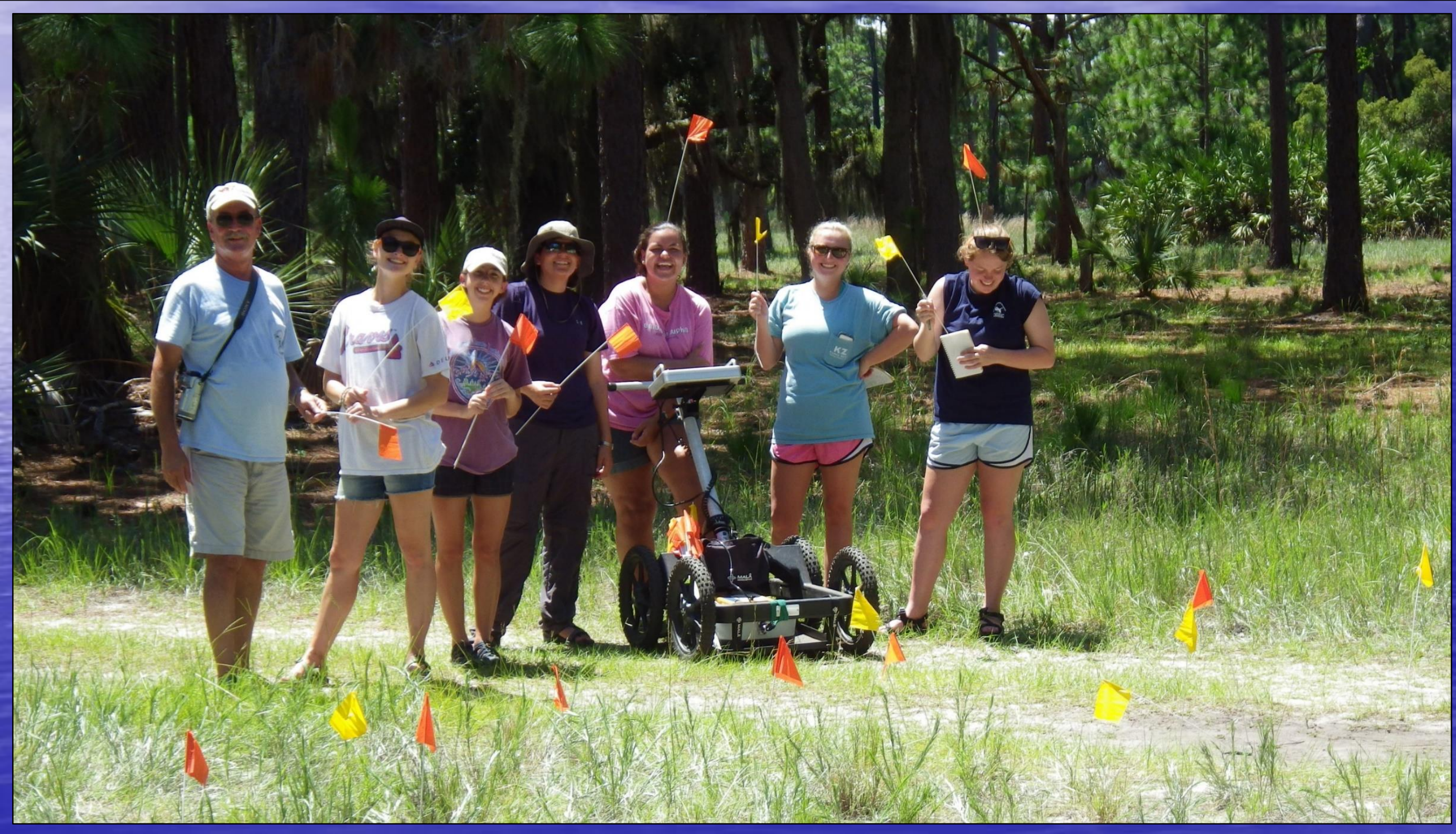




\section{Class of 2018: pre-departure group picture}

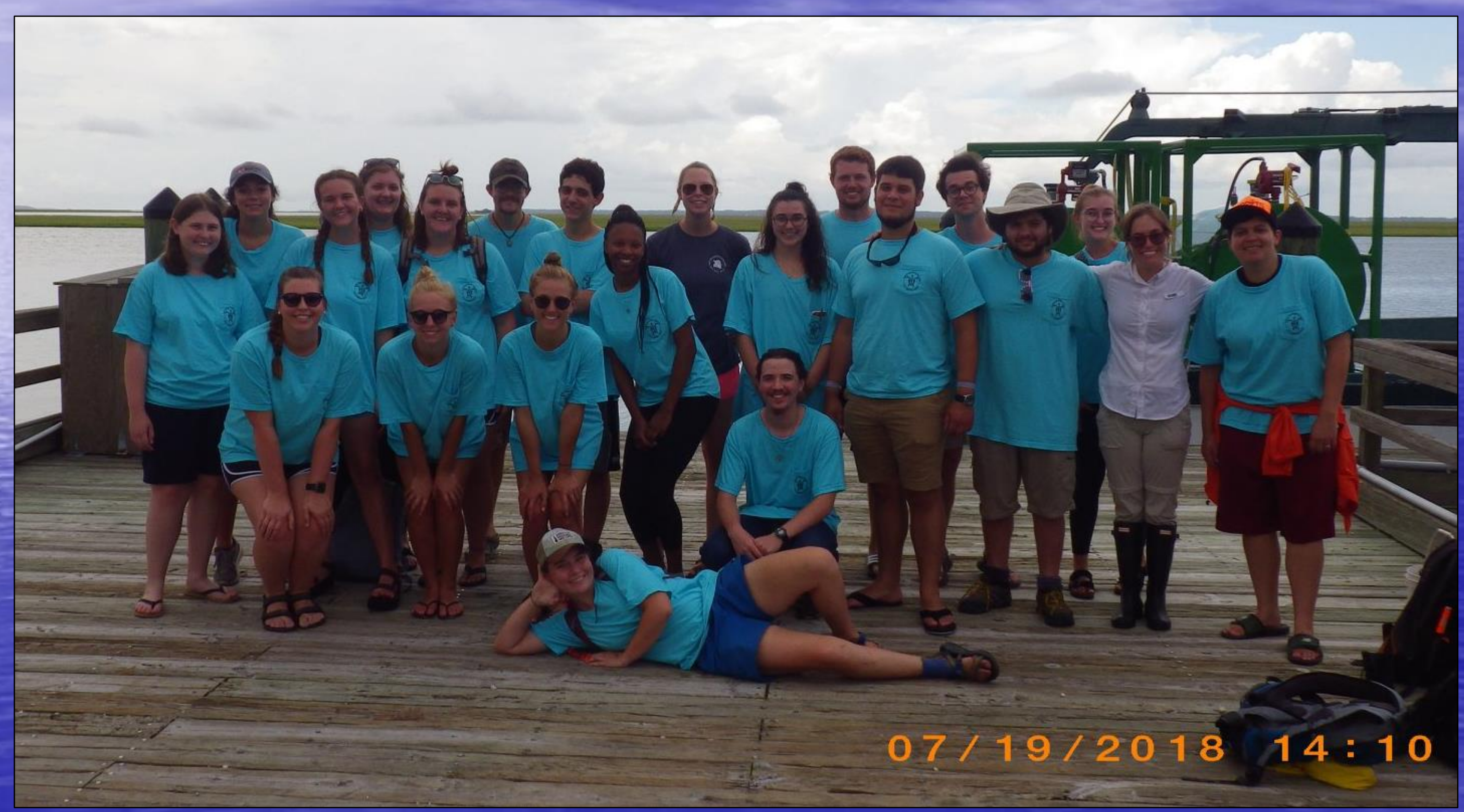




\section{Summary \& Closing Comments}

- Two course package ( 8 hrs of elective science credit)

- Delivers hands-on integrated, interdisciplinary experience

Strengths:

- Field-based dynamic "class room" (place-based learning)

- Service learning component (10 days of conservation work)

- Learning through experience (hands on)

- Female science majors dominate enrollment (STEM positive impact)

- Provides valuable experience and contacts for students pursuing careers in wildllife conservation

- Provides valuable experience and contact for pre-veterinary students 